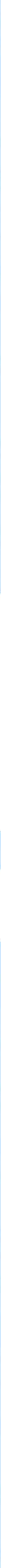


I. Crônicas

1. Crônicas da atualidade do Direito Internacional ......................................................16

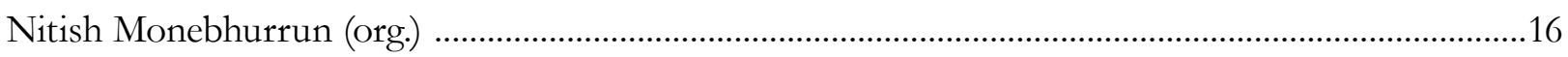

2.Decisões da Corte Internacional de Justiça e do Tribunal Internacional Sobre o Direito do Mar

Nitish Monebhurrun

José Eduardo Siqueira

3. Crônicas do direito internacional dos inVestimentos

Nitish Monebhurrun

\section{Os Vinte Anos dA OMC}

EXPORT CONTROLS AS INDUSTRIAL POLICY ON NATURAL RESOURCES: REGULATORY LIMITATIONS ON CHINA - RAW MATERIALS AND CHINA - RARE EARTHS CASES.

Gustavo Ferreira Ribeiro

O problema da espionagem econômica internacional: Seria a Organização Mundial do CoMÉRCIO O FORO ADEQUADO PARA SUA APRECIAÇÃO?

Humberto A.Vasconcelos Lima

Naiana Magrini Rodrigues Cunha

International Standards for Intellectual Property Rights Protection: a reflection on CLIMATE-FRIENDLY TECHNOLOGY TRANSFER.

Guihong Zhang

Jiani Jiang

Can Wang

Os vinte anos da OMC, suas conquistas e desafios: uma análise do Brasil e o Sistema de SoLUÇõES DE CONTROvÉRsias

Etiene M. Bosco Breviglieri

Luciano Meneguetti Pereira

A relação entre os tratados multilaterais ambientais e os acordos da OMC: é possível CONCILIAR O CONFLITO?

Fabio Costa Morosini,

Luisa Zuardi Niencheski 
Um desafio na Organização Mundial do Comércio: viabilidade de um acordo plurilateral SOBRE ENERGIA

Matheus Linck Bassani

ContrataÇõES PÚBLICAS NO ÂMBITO DA OMC: A POLÍTICA LEGISLATIVA BRASILEIRA À LUZ DO DIREITO AO DESENVOLVIMENTO

André Jansen do Nascimento

Governança global e a Organização Mundial do Comércio: desafios impostos pelo novo MANDATO DE DESENVOLVIMENTO 218

Letícia de Souza Daibert

Ana Luísa Soares Peres

Vinte Anos de Crise para a África? Poder, Assimetrias e a Abordagem Liberal da OMC.....239 Igor Abdalla Medina de Souza

Os MECANISMOS DE INDUÇÃo AO CUMPRIMENTO NO ÂMBITO DA OMC .258

Fernando Lopes Ferraz Elias

A promoção de accountability na Organização Mundial do Comércio: uma análise horiZONTAL E VERTICAL.

Celso Henrique Cadete de Figueiredo

LA OMC y EL PROCESO DE GLOBALIZACION DE LA REGULACIÓN ALIMENTARIA

Maria Eugenia Marichal

O ACORDO GATS E SUA APLICAÇÃo AOS SERVIÇOS DO COMÉRCIO ELETRÔNICO .322

Gleisse Ribeiro Alves

A OMC E o Regionalismo do SÉCUlo XXI: ESTRATÉgia de IMPOSIÇÃo de MODELOS NORMATIVOS? .. 337 Camilla Capucio

A organização mundial do comércio e a china: direito de Propriedade e propriedade inteLECTUAL NO PAÍS

Dos contenciosos NA OMC COM ENFOQUE EM RESTRIÇõES Às EXPORTAÇõEs DA CHINA .363

Marco Antônio Alcântara Nascimento 
O redimensionamento da OMC no trato dos Acordos Comerciais Regionais.

Alice Rocha da Silva

\section{Outros Temas}

Derechos Humanos EN LA REALIDAD ACTUAL: LA GLOBALIZACión Y EL MUlTiCUlTuRALISMo

David Falcão

IMUNIDADE DE JURISDIÇÃo do ESTAdo E REPARAÇÃo CIVIL PELA PRÁTICA DE TORTURA: O CASO ZaHRA

KAZEMI V. REPÚBLICA ISLÂMICA DO IRÃ

Patrícia Maria Lara Abreu

Rodrigo Otávio Bastos Silva Raposo

INTERREgIONAL ORganizations (IROS) IN EUROPE: NEW SUBJECTS OF CONTEMPORARY INTERNATIONAL LAW?

Davorin Lapas

A CONEXÃo entre os direitos humanos e A CORRUPÇão

Gabriela Alves Mendes Vieira

Marcelo Dias Varella

GRUPO DE SOCIEDADES: INSTRUMENTO JURÍDICO DE ORGANIZAÇÃo DA EMPRESA PLURISSOCIETÁRIA......495

Daniel Amin Ferraz 


\title{
Grupo de sociedades: instrumento jurídico de organização da empresa plurissocietária
}

\author{
Group of Companies: legal instrument to organize \\ multi-corporate companies
}

Daniel Amin Ferraz*

\section{Resumo}

O grupo de sociedades é, hoje em dia, o instrumento jurídico, por excelência, de inserção da grande empresa transnacional nos mercados globais. Trata-se de técnica jurídica de constituição da empresa plurissocietária, permitindo a concentração de conglomerados que atuam em distintos países e influenciam o desenvolvimento do mercado nestas regiões. Por outro lado, frequentemente é o grupo de sociedades, na doutrina jurídica pátria, confundido com o gênero concentração empresarial, e não caracterizado como mais um instrumento à disposição do mercado para as concentrações desejadas. Importa, assim, distinguir tal instrumento de outros instrumentos de concentração e cooperação empresarial, tais como a Fusão, a Cisão, a Holding e a Joint Venture, promovendo-se a caracterização do grupo como o mais moderno instrumento jurídico plurisocietário de concentração empresarial.

Palavras-chave: Grupo de sociedades. Empresa plurissocietária. Fusão. Cisão. Holding. Joint venture.

\section{Abstract}

The group of companies is, latterly, the only legal instrument in order to insert the great transnacional company into global markets. It is a legal technique that creates the multi coporate company, allowing the concentration of conglomerates that operate in different countries and influence the market development in these regions. On the other hand, often the group of companies, in the national legal doctrine, is mistaken to the business concentration genus, rather be a instrument at hand to the market, to the desirable concentrations. Highlight, thus, the distinguish between this instrument to some other concentrarion and businees cooperation instrument, such as Amalgamation, Spin-off, Holding and Joint Venture, promoting the characterization of the group even with the most recent company concentration multi corporate legal instrument.

Keywords: Corporate groups. Multi corporate company. Amalgamation, Spin-off. Holding. Joint Venture.

* Artigo convidado

Mestre em Direito Empresarial pela Universidade de Coimbra, Portugal; Doutor em Direito Empresarial Internacional pela Universidad de València, Espanha; Professor do Mestrado/Doutorado do UniCeub - Centro Universitário de Brasília; Advogado titular de Amin, Ferraz Coelho Advogados Associados; daniel.amin@afcadvogados.adv.br 


\section{Introdução}

O desenvolvimento do mundo moderno induz, cada vez com maior intensidade, à realização de empreendimentos comuns.

A transnacionalização das empresas, que as faz olhar o mundo como um único mercado, estimula em certa medida a concorrência (com a atuação internacional dos grupos) e exige formas associativas novas para a conquista ou a manutenção de determinadas áreas de domínio.

Tal objetivo implica constante determinação das empresas a favor da diminuição dos custos, com a obtenção de economia de escala. Ademais, o simples crescimento das atividades produtivas, por meio do instrumento de concentração básico (fusão), pode gerar não uma diminuição de tais custos fixos, senão, seu incremento, derivado de um gigantismo da atividade produtiva ${ }^{1}$.

Por outro lado, a necessidade de tecnologia com inovações constantes impõe a necessidade de volumosos investimentos em investigação, com riscos elevados que uma empresa isolada não suportaria. Além disso, o volume de informação que requer a atividade global e tecnológica se entende melhor quando as empresas atuam conjuntamente, em determinado setor da atividade. É importante sublinhar que o melhor controle dos mercados regionais atua como característica fundamental para a busca, pelos empresários, de novas formas associativas ${ }^{2} /{ }^{3}$.

Nesta breve introdução, vale referir que o grupo de sociedades, na doutrina pátria, tanto em sua vertente econômica de análise, mas, precipuamente, em seu viés jurídico é, com frequência, confundido com o gênero concentração empresarial, e não como uma espécie do mesmo.

Assim, se analisada a tipologia dos grupos de sociedades, permitindo contextualizar este instrumento jurídico como uma espécie mais do gênero concentração empresarial (e não como o gênero em si),

1 PEREIRA NETO, Mario. Joint Ventures com a União Européia. São Paulo: Aduaneiras, 1995. p. 33.

2 LAMY FILHO, Alfredo; PEDREIRA, José Luiz Bulhões. $A$ Lei das S.A. Rio de Janeiro: Renovar, 1992. p. 98.

3 No mesmo sentido, todavia agregando a ideia de permitir ao empreendimento comum uma sinergia psicológica entre os entes sociais, facilitando assim a inserção comercial dos mesmos no país acolhedor de investimento, veja: LANGEFELD-WIRTH, Klaus. Les Joint Ventures internationals. Paris: GLN Joly editions, 1992. p. 7. cumpre sublinhar as diferenciações básicas deste com outros instrumentos de concentração e cooperação empresarial.

Importa dizer que não se fará análise exaustiva de todos os instrumentos de concentração empresarial existentes, já que praticamente impossível tal desiderato. Impossível porque, na atualidade, instrumentos de concentração existem tantas quantas operações empresariais existentes no mercado. Assim que, seguidamente, se analisará, comparativamente, o grupo de sociedades com os instrumentos de concentração e cooperação com os quais é confundido de forma mais frequente, quais sejam: 1) fusão; 2); cisão; 3) bolding, e; 4) joint venture.

Observe-se que se realizará estudo mais aprofundado da join venture, já que este instrumento jurídico, em suas duas vertentes (corporated joint venture $e^{4}$ e uncorporated joint venture ${ }^{5}$ ), é com maior frequência confundido com o grupo de sociedades.

Finalmente, ressalta-se que no presente texto, seguindo a moderna teoria do direito empresarial, utiliza-se o vocábulo empresa como sinônimo de empresário, referindo-se aos dois de forma indistinta.

4 Poderia haver confusão com o grupo de sociedades de base societária, vez que ambos os instrumentos tem natureza jurídica de negócio societário, não estando qualificados no campo dos negócios obrigacionais, mas sim societários (plurilaterais ou estatutários).

5 Poderia haver confusão com o grupo de sociedades de base contratual, já que os dois instrumentos possuem natureza jurídica de negócio obrigacional. Neste ponto, importante ressaltar que o grupo de sociedades de base contratual estará classificado como negócio jurídico complexo, no âmbito obrigacional. Por sua vez, a joint venture contratual, no Brasil consórcio de empresas, será também, sempre, negócio obrigacional, podendo ser classificado como bilateral (se não há controle) ou complexo (quando exista controle de uma das co-ventures sobre as demais).

6 Cumpre referir que para o Direito Mercantil clássico há que se falar em distinção entre empresário, empresa e estabelecimento comercial. Assim, por empresário entende-se o individuo, pessoa física ou jurídica, que desenvolve a atividade mercantil em nome próprio. Observe-se que o empresário pode ser registrado na junta comercial (empresário regular) ou não registrado (empresário irregular ou de fato). Por sua vez, o estabelecimento comercial é definido como um bem corpóreo, infungível, composto de bens corpóreos e incorpóreos, fungíveis e infungíveis, sempre móveis. Saliente-se que o imóvel não é elemento do estabelecimento comercial. Finalmente, a empresa, no Direito mercantil clássico, é entendida como a mera atividade empresária, a organização dos fatores de produção: capital, trabalho e informação. Assim, é entendida a empresa como objeto de direito e não sujeito, sendo passível de negociação no mercado, de forma autônoma e independente da figura do empresário e, até mesmo, do estabelecimento mercantil. Por isso mesmo, estaria ela a empresa, em tese, equiparada à mercadoria. Por seu turno, para o moderno Direito Empresarial, não há que se fazer distinção entre empresa e empresário, sendo usados, tais vocábulos, como expressões 
2 Breve tipologia do grupo de sociedades e suas distinções jurídico-doutrinárias: instrumento societário ou obrigacional?

O grupo de sociedades é, hoje em dia, o instrumento, por excelência, de organização da empresa transnacional.

Técnica jurídica apurada pode fundamentarse em três modalidades distintas, a saber: grupo de sociedades de base societária, grupo de sociedades de base contratual, grupo de sociedades de base pessoal ${ }^{7}$.

Por grupo de sociedades de base societária entendese a organização do capital que permitirá coparticipação societária, determinante de um sistema de controle que gere o exercício do poder de gestão de uma sociedade, a sociedade mãe, sobre outros entes societários, as sociedades filhas.

Importa ressaltar que nessa modalidade de grupo (de base societária) o instrumento de participação, constituído entre os membros do grupo, terá natureza jurídica de negócio societário, em sua classificação de negócio jurídico plurilateral (se entre sociedades limitadas) ou estatutário (se entre sociedades anônimas).

Por outro lado, para a constituição de um grupo de sociedades de base contratual, não há que se falar em coparticipação societária, mas, tão somente, na realização de negócios jurídicos de natureza obrigacional.

Assim, em um grupo de sociedades de base contratual, três são os elementos essenciais caracterizadores do grupo, quais sejam:

sinônimas. Por todos, veja-se, no sentido do referido: CARVALHO, Orlando de. Critério e estrutura do estabelecimento comercial: o problema da empresa como objecto de negócios. Coimbra: Coimbra, 1967. A respeito da conceituação do estabelecimento comercial, veja-se: BORGES, João Eunápio. Curso de Direito Comercial Terrestre. Rio de Janeiro: Forense, 1959. p. 283. v. 1. A respeito da definição jurídica de empresa, veja-se: MENDONÇA, José Xavier Carvalho de. Tratado de Direito Comercial Brasileiro. Rio de Janeiro: Freitas Bastos, 1957. p. 482. v. 1. Com relação à definição de empresário, veja-se: FERREIRA, Waldemar Martins. Tratado de Direito Mercantil Brasileiro: o comerciante. Rio de Janeiro: Freitas Bastos, 1939. p. 23. v. 2.

7 As duas primeiras modalidades são as que interessam ao objeto do presente artigo. O grupo de base pessoal é aquele que se dá em virtude da repetição de pessoas físicas nos conselhos de administração das distintas pessoas jurídicas, com capacidade para administrar as mesmas como se se tratasse de uma única personalidade jurídica. Para aprofundamento da tipologia dos grupos de sociedade de base pessoal, veja-se, entre muitos: FERRAZ, Daniel Amin. El Grupo de Sociedades como Mecanismo de Desarrollo de los Países de Periferia. Revista de Direito, Viçosa, MG, v. 1, n.1, p. 205-238, 2004.
A existência de uma relação obrigacional, objeto de contrato (geralmente negócio jurídico complexo), entre as partes;

$O$ poder de direção em controle derivado de tal contrato, em favor de uma das partes e em detrimento dos demais entes societários e;

A dependência econômica também decorrente do desenvolvimento da atividade do grupo.

Claro está, portanto, que para a caracterização do grupo de sociedades de base contratual será fundamental a existência de relações jurídicas contratuais, obrigacionais ${ }^{8}$, entre os membros do grupo, e que tais relações tenham o condão de gerar poder de direção e controle e dependência econômica.

Do até aqui analisado conclui-se que, em sua classificação, o grupo de sociedades possui natureza múltipla, já que caracterizado como negócio jurídico societário (grupo de base societária) ou negócio jurídico obrigacional (grupo de base contratual).

Passa-se, a seguir, a promover-se a distinção entre os grupos de sociedades com estas duas categorias empresariais, quais sejam, os instrumentos de concentração empresarial (negócios societários de fusão, cisão e holding) e os instrumentos de cooperação empresarial (negócio obrigacional de joint venture) ${ }^{9}$.

\section{0 grupo de sociedades de base societária e outros instrumentos de concentração empresarial}

A seguir, aborda-se a distinção do grupo de sociedades de base societária com outros instrumentos de concentração empresarial, quais sejam, a fusão, a cisão e a holding.

Salienta-se que a eleição de tais instrumentos de concentração possui sua lógica jurídico-econômica.

Assim, a fusão foi selecionada por haver sido o instrumento de concentração por excelência, o mais praticado no desenvolvimento econômico e, em virtude do tempo, provavelmente, o mais experimentado.

Por seu turno, a escolha recaiu sobre a cisão para esta análise comparativa com o grupo de sociedades

8 V.g., negócios de distribuição estrito senso, de fornecimento, negócios de franquia, negócios de agência, etc.

9 Para um aprofundamento quanto à tipologia dos grupos de sociedades, entre muitos, veja-se: FERRAZ, Daniel Amin. La concentración empresarial en el comercio internacional - El control de los grupos de sociedades en los EE.UU., la UE y MERCOSUR: un análisis comparado. Valencia: Editorial de la Universidad de Valencia, 2004. 
de base societária por ser qualificada, muitas das vezes, como um instrumento de desconcentração.

Entretanto, ao final, quedará claro que essa "desconcentração" é, em realidade, uma técnica apurada de conversão da empresa plurissocietária em movimento atomístico de concentração empresarial, com dispersão do capital, para dominação de mercado.

Por fim, selecionou-se a figura da holding porque, provavelmente, será este instrumento de concentração que mais se assemelha ao grupo de sociedades de base societária. Ficará demonstrado, contudo, que estes instrumentos não se confundem, sendo mesmo, muitas das vezes, complementários.

A seguir, passa-se a análise de tais elementos diferenciadores, com a ressalva de que o objetivo não é o de esgotar a fundamentação de tais institutos jurídicos, mas, tão somente, promover distinções entre eles e o grupo de sociedades de base societária, para, aí sim, conseguir um melhor enquadramento deste instrumento jurídico de concentração empresarial.

\subsection{Fusão}

No seio da União Européia - UE, a partir da Terceira Diretiva relativa à fusão da S.A. ${ }^{11}$, promoveuse harmonização da matéria. Assim, alguns elementos

10 Veja-se, para aprofundamento do estudo da fusão, entre outros: BEGG, P. F. C. Corporate Acquisitions and Mergers. London: Graham \& Trotman, 1986. p.19 e ss.; WEINBERG, M. A. Take-overs and Mergers. London: Sweet \& Maxwell, 1979; BERCOVITZ, Alberto. La Fusión de Sociedades. In: La Reforma del Derecho Español de Sociedades de Capital. Madrid: Universidad Complutense, 1987, p. 631 e ss.; BERTREL, Jean; JEANTIN, Michel. Fusions et acquisitions de sociétés commerciales. Paris: Litec, 1989, p.47; CHEMINADE, Y. La Nature Juridique des Fusions. In: RTDC p. 15-37, 1970. ; MARTIN, G. La Notion de Fusion. In: RTDC, p. 269-298, 1978. ; SANTAGATA, Carlo. La Fusione fra Società. Napoli: Morano, 1964, p. 153 e ss; TANTINI, Giorgio. Transformazione e Fusione delle Società. In: Tratatto di Diritto Comérciale e di Diritto Pubblico dell'Economia, v. 8., Padova: Cedam, 1985; VENTURA, Raúl. Fusão, Cisão, Transformação de Sociedade. Coimbra: Almedina, 1990, p. 5 e ss.; ANDREU MARTÍ, $\mathrm{M}^{\mathrm{a}}$ del Mar. La nulidad de la fusión de sociedades. Pamplona: Aranzadi Editorial, 2002, p.25 e ss.; VAÑÓ VAÑÓ, Maria José. Fusión heterogénea y cesión global en el sector bancário. Valencia: Tirant lo Blanc, 2001, p. 41 e ss. A respeito da classificação da fusão, vejase, especialmente: BIANCHI, Giorgio. Le Operazioni di Fusione. Torino: Unione Tipografico-Editrice Torinese, 2000, p. 6 e ss.; a respeito da natureza jurídica da fusão, entre outros, veja-se: SACARDULLA, Francesco. La Transformazione e la Fusione delle Società, In: Trattato di Diritto Civile e Comérciale. CICU, Antonio; MESSINEO, Francesco; MENGONI, Luigi. v. 30, t. 2., Milano: Giuffrè editore, 2000, p. 308325.; a respeito do sistema de avaliação de bens das sociedades na fusão, veja-se: PALEA, Vera. Il Rapporto di Cambio nelle Operazioni di Fusione e di Scissione. Torino: Giappichelli Editore, 2000, p. 87-105.

11 Tercera Directiva 78/855/CEE do Conselho, de 09 de outubro de 1978 (Diário Oficial L 295 de 20.10.1978). seriam comuns nas legislações nacionais relativos às fusões.

Os regimes nacionais delimitam a fusão de sociedades mediante elementos comuns: a concepção procedimental; os elementos configuradores ou efeitos parciais, subsequentes à culminação do procedimento traçado para a realização da fusão - a extinção sem liquidação de alguma sociedade, a sucessão universal em todos os direitos e obrigações das sociedades extintas por parte da nova sociedade criada e a entrada dos sócios das sociedades que se extinguem à sociedade nova, mediante a entrega aos mesmos de ações, participações ou cotas - e as modalidades que podem revestir essa instituição única - fusão por absorção ou incorporação e fusão mediante criação de uma nova sociedade $^{12}$.

Conceitualmente, a fusão é um procedimento jurídico através do qual duas ou mais sociedades agrupam seu patrimônio, ativo e passivo, em uma única sociedade, seja nova (fusão criação) ou antiga (fusão absorção). Promoverão, para tal, a prévia dissolução de todas as sociedades que se fusionam (fusão criação), ou de todas menos uma, que mantêm seu patrimônio e sua personalidade jurídica (fusão absorção) ${ }^{13}$.

A fusão de sociedade se diferencia do grupo de sociedades em vários aspectos. Assim, a fusão constitui operação econômica-jurídica de concentração intersocietária que gera, por definição, a extinção da personalidade coletiva das sociedades envolvidas, ao passo que o grupo pressupõe justamente sua manutenção ${ }^{14}$. Esta diferença, unidade ou pluralidade jurídica da empresa emergente, ${ }^{15}$ é absolutamente fundamental para a compreensão do alcance diverso destas duas técnicas jurídicas de concentração empresarial, em termos de eficiência econômica, financeira, organizacional e até jurídica.

12 LARGO GIL, Rita. La fusión de sociedades mercantiles: fase preliminar, proyecto de fusión e informes. 2. ed. Madrid: Civitas, 2000. p.134.

13 Veja-se, por todos para a definição e tipologia da fusão: BROSETA PONT, Manuel. Manual de derecho mercantil.10. ed. Madrid: Editorial tecnos, 2000. p. 342.

$14 \mathrm{Na}$ fusão absorção, a sociedade absorvida transmite a totalidade de seu patrimônio para a sociedade absorvente, desaparecendo como ente jurídico. Por outro lado, na fusão criação, as sociedades fusionadas se extinguem e transferem todo o respectivo patrimônio para uma nova e distinta sociedade.

15 A fusão configura-se como uma empresa unisocietária. Por sua vez, os grupos de sociedades criam uma empresa plurisocietária. 
Por fim, fator determinante na União Europeia para a manutenção das fusões é sua estrutura econômica. Assim, na UE existem 15 milhões de PYMES frente aos 5 milhões existentes nos Estados Unidos. Ainda que, desde o ponto de vista da criação do emprego e das novas tecnologias, tem papel relevante, também é necessário potencializar sua concentração. Tal fato ocorre não somente desde a perspectiva do incremento de sua competitividade, mas também de sua sobrevivência, em um mercado fortemente globalizado, ao supor que a fusão permite vantagens tais como a redução nos custos empresariais de financiamento e da produção $^{16}$.

\subsection{Cisão}

A cisão de uma sociedade é, em contraposição à fusão de sociedades, um procedimento econômico e jurídico de desconcentração empresarial, de especialização e racionalização empresarial, de regionalização da empresa, ou o mecanismo menos oneroso e traumático de separação de acionistas em sociedades muito personalíssimas, com grupos ou sócios bem diferenciados e interesses contrapostos ${ }^{18}$.

À diferença da fusão, a cisão de sociedades constitui técnica de desconcentração ou descentralização societária (demerger), que consiste na operação jurídicoeconômica pela qual uma única sociedade procede à divisão de seu próprio patrimônio, total ou parcialmente, com ou sem extinção da respectiva personalidade jurídica, sendo as partes seccionadas transmitidas para uma nova sociedade ou uma sociedade já existente ${ }^{19}$.

16 SÁNCHEZ MIGUEL, María Candelas. Las fusiones transfronterizas y el derecho de la competência. In: Derecho de Sociedades.. Madrid: McGrawHill, 2002. p. 5088. v. 5.

17 Veja-se, entre outros: MISHKIN, Walter: Techniques in corporate reorganizations. New York: Publisher House, 1972. p. 46; SCHIPPER, K; SMITH, A. The Corporate Spin-Off Phenomenon. In: The Revolution in Corporate Finance. Oxford: Basil Blackwell, 1986. p. 437-444.; SIEGEL, Harold. When Corporations Divide: a financial and legal analysis. In: 79 HarvLR, p. 534-577, 1966.; ROJO, Angel. La Escisión de Sociedades. In: La Reforma del Derecho Español de Sociedades de Capital. Madrid: Universidad Complutense, 1987. p. 663-710; FERREIRA, Durval. Cisão de Sociedades. Coimbra: Almedina, 1985, p. 7.

18 FRAILE BARTALOMÉ, Gregorio; CLEMENTE CLEMENTE, Vicente. Fusiones y Escisiones en las Sociedades Anónimas. Valencia: CISSPRAXIS, 2001. p. 59.

19 Quando se confronta a cisão com a fusão, caracterizando-se a última como uma operação de concentração e a primeira como de desconcentração, toma-se as expressões em um sentido puramente funcional, a fim de sugerir o diferente modus operandi de sua realização.
Assim, a cisão pode constituir um instrumento adequado para a descentralização, desconcentração ou especialização empresariais, motivadas pelas razões de racionalização econômica ou, inclusive, como consequência da execução de políticas antimonopolísticas ${ }^{20}$.

Por meio de uma operação de cisão, uma sociedade pode:

Destacar tão somente uma parte de seu patrimônio para constituir uma nova sociedade (cisão - criação);

Dissolver-se, dividindo todo o seu patrimônio em distintas partes, destinadas à constituição de novas sociedades (cisão - dissolução);

$\mathrm{Ou}$, inclusive, promover a respectiva fusão com sociedades já existentes (cisão - fusão) ${ }^{21}$.

Em suas duas primeiras modalidades, a cisão possui algumas similitudes com o grupo de sociedades.

Assim, tratando-se de uma operação jurídicoeconômica que permite veicular uma lógica de repartição de uma atividade econômica originariamente unitária entre vários entes societários juridicamente autônomos, pode constituir o embrião da formação de um grupo de sociedades.

Tal afirmação é reforçada pelas circunstâncias de que os sócios da sociedade cisionada vêm a dominar as sociedades, novas ou já existentes, destinatárias das parcelas patrimoniais destacadas. Ademais, as operações de cisão-criação ou cisão-dissolução podem constituir métodos alternativos funcionais de constituição de um grupo aos mecanismos de domínio total originário ${ }^{22}$.

É claro que, desde um ponto de vista econômico das empresas, as duas figuras devem considerar-se verdadeiras técnicas jurídicas de suporte de concentração econômica. Uma operará, sobretudo, na fase de expansão pura de uma empresa, a outra em uma fase de respectiva reorganização interna. Veja nesse sentido: CHAMPAUD, Claude. Le Pouvoir de Concentration de la Société par Actions. Paris: Librairies Sirey, 1962. p. 187.

20 RODRÍGUEZ ARTIGAS, Fernando; URIA, Rodrigo; MENÉNDEZ, Aurelio; OLIVENCIA, Manuel. Comentario al régimen legal de las sociedades mercantiles: transformación, fusión y escisión de la sociedad anónima., Madrid: Editorial Civitas, 1993, p. 19-20. v. 3, t. 9. 21 Sobre as varias formas modernas de cisão veja-se: EISENBERG, Melvin. The structure of the corporation: a legal análisis. Boston: Little Brown, 1975. p. 255.

22 A operação de cisão, particularmente cisão-criação, constitui assim um método de constituição de grupos de grupos societários, alternativo ao mecanismo de domínio total originário. As duas figuras são idôneas para realizar a chamada expansão externa da empresa, operando a transformação de uma estrutura originariamente unisocietária em uma estrutura plurisocietária.

Sem embargo, ainda que exista esta identidade funcional, há 
Todavia, deve-se sublinhar que, em si mesma, a cisão constitui uma operação técnico-jurídica neutral. Tratase, tão somente, de um processo de descentralização jurídica, organizativa e patrimonial de uma empresa unitária, sem determinar o respeito das relações futuras dos entes emergentes ${ }^{23}$, e muito menos a subordinação de todos esses a uma direção econômica unitária, exercida pela sociedade cisionada, o que aconteceria no grupo.

\subsection{Holding ${ }^{24}$}

O conceito de holding é utilizado para designar aquelas sociedades que têm como objeto a gestão de uma carteira de títulos.

Neste contexto de sociedades com um objeto financeiro, cabe distinguir dois tipos fundamentais, com a finalidade subjacente da já aludida gestão:

A) Por um lado, existem sociedades que têm por objeto a gestão de uma carteira de participações com uma simples finalidade de rentabilidade dos capitais investidos. São estas as chamadas sociedades financeiras ou sociedades de investimento ${ }^{25}$.

diferenças entre as duas figuras. Desde logo, ao passo que a cisão simples pode ser operada por qualquer tipo societário, a constituição de uma sociedade unipessoal somente poderá ser operada sob a forma de uma sociedade anônima, quanto à sociedade criada, nova. Por outro lado, a diferença está no âmbito dos respectivos orçamentos de criação. Assim, ao passo que na cisão os bens destacados devem ser determinados, os ingressos na sociedade unipessoal podem constituir-se em bens de qualquer espécie.

Finalmente, no âmbito do regime jurídico aplicável. Uma primeira diferença tem que ver com a posição relativa dos sócios e administradores da sociedade cisionada e criadora, resultante da operação em análise. Ao passo que na cisão-criação as partes sociais na nova sociedade são atribuídas aos sócios da sociedade cisionada, mantendo estes um poder de intervenção na condução dos negócios sociais da nova sociedade, na operação de domínio total não passará o mesmo, já que as partes sociais passam a pertencer, exclusivamente, à própria sociedade criadora (o que equivale a um reforço, por via indireta, dos poderes dos órgãos de administração em detrimento do colegiado dos sócios). Veja, neste sentido: ANTUNES, José A. Engrácia. Os direitos dos sócios da sociedade-mãe na formação e direção dos grupos societarios. Porto: UCP, 1996. p. 45.

23 Que costumam evoluir no mercado, ou como entidades independentes, ou como unidades dependentes entre si.

24 Veja: DAEMZ, Herman. The bolding company and corporate control. Boston: Leiden, 1978. p. 51; GALGANO, Francesco. Qual è l’oggetto sociale della holding? CeIm, v. 2, p.327-343, 1986. ; LIBONATI, Berardino. holdings e investment trusts. Milano: Giuffrè, 1977, p.32. ; VENTURA, Raúl. Participações unilaterais de sociedades em sociedades e sociedades gestoras de participacões noutras sociedades. In: XXIX RSI, p. 19-101, 1980.

25 HAMEL, Joseph. Les sociétés dinvestissement. Paris: A.N.S.A. 128, 1960. p.22.; SENN, Georges. Les sociétés de investissement en droit
B) Por outro lado, há sociedades que têm por objeto a gestão de participações sociais com o objetivo de adquirir o controle das sociedades, por meio do exercício dos direitos sociais inerentes ao capital (máximo direito ao voto). Por este segundo tipo de sociedades se costuma reservar, na doutrina especializada, a denominação de sociedade bolding $g^{26}$.

A holding constitui um instrumento valioso de reorganização dos grupos de sociedades. Sem embargo, não se pode confundir com o próprio grupo.

Enquanto este último constitui uma forma organizativa (informal) da atividade econômica da empresa moderna como empresa plurissocietária; a holding representa tão somente uma forma organizativa (formal) do respectivo ápice hierárquico. Nesse sentido, aparece como uma das modalidades jurídicosocietárias possíveis que podem revestir a sociedade matriz de um grupo. Naturalmente, a adoção da forma holding por uma determinada sociedade constitui um forte indício da existência de um grupo de sociedades, já que seu objeto contratual (constituído pela administração de participações sociais como forma indireta do exercício de atividades econômicas) está particularmente destinado a organizar o exercício de uma direção econômica unitária da sociedade sobre seus participantes.

\section{français et droit comparé. Paris: Sirey, 1956.}

26 No quadro das sociedades cujo objeto social consiste na gestão de uma carteira de participações sociais, aquele que diferencia os dois tipos societários referidos é o objetivo ou finalidade para gestão da mesma carteira de participações. No primeiro caso, a gestão das participações sociais constitui um fim em si mesmo, no sentido de que a sociedade participante pretende tão somente maximizar a rentabilização do investimento de capitais feita nas sociedades participadas, seja mediante a percepção de dividendos (lucros), seja pela obtenção de mais valias mediante a rotação da carteira de títulos mobiliários. Importante sublinhar como ponto característico deste tipo de participação o feito de que a sociedade não pretende nenhuma espécie de controle, mas, tão somente, ganhos de capitais.

No segundo caso, pelo contrário, a gestão de participações sociais constitui um meio em relação a um fim, ou seja, constituem um puro instrumento de controle e gestão indireta dos negócios das sociedades participantes. No âmbito das próprias sociedades holdings poderia, ainda, proceder-se ulterior classificação. Assim, estariam classificadas as holdings entre aquelas que tem por objeto tão somente a gestão de uma carteira de participações sociais entre outras sociedades como forma indireta de exercício de atividades econômicas (boldingspuras), e aquelas que, além de ter as participações sociais e gerir a carteira de participações exercem outras atividades, de natureza industrial ou comercial, no âmbito do respectivo objeto social (holdings mistas). 
Não obstante, deve-se apontar que nada pode ser inferido de tal circunstância, nem em geral nem em definitivo, ademais da natureza e intensidade das relações existentes de coligação intersocietárias, dependendo tudo, em última instância, da apreciação das circunstâncias de cada caso em concreto.

Assim, uma sociedade bolding poderá:

a) ser titular de uma vasta estrutura de situações de coligação intersocietária, desde as relações de grupo propriamente ditas (por meio de participações totalitárias que assegurem o domínio total das participantes), até as relações de domínio (máxima, por meio de participações minoritárias);

b) bem como as próprias relações de simples participação (participações oscilantes entre 10\% e 50\%);

c) inclusive gerir participações irrelevantes desde o ponto de vista de aplicação de uma disciplina especial das sociedades coligadas.

Conclui-se, dessa forma, que a sociedade holding não se confunde com o grupo de sociedades, podendo ser, tão somente, uma das formas de organização jurídica da matriz do grupo (ou sociedade mãe).

\section{0 grupo de sociedades a Joint Venture}

O contrato de joint venture é uma das espécies de negócio associativo. Constitui-se mediante a associação de empresas em uma terceira corporação (incorporated joint venture - joint venture societária), ou mediante a constituição de consórcios de empresas (unincorporated joint venture - joint venture contratual).

Poderá se realizar em áreas estritamente tecnológicas (v.g., investigações em biotecnologia); em exploração mineral; entre empresas estrangeiras e nacionais (para vencer barreiras tarifárias); para mobilizar capitais e realizar obras que requeiram tecnologias não dominadas por uma única empresa. É precisamente por esse amplo âmbito de atuação que as joint venture alcançaram, atualmente, um grande desenvolvimento, com forte presença no mercado mundial.

É importante notar que a joint venture, em sua vertente societária, classifica-se como um instrumento de concentração empresarial. Por seu turno, em sua vertente contratual, unincorporated joint venture (consórcio de empresas no Direito brasileiro ${ }^{27}$ ), classifica-se como um instrumento de cooperação empresarial.

27 Lei 6.404, de 15 de dezembro de 1976, publicada no DOU
Cumpre ressaltar que a joint venture muito se aproxima do grupo de sociedades. Assim, também como este, pode ser classificada como negócio jurídico societário (plurissocietário ou estatutário incorporated joint venture/grupo de base societária), ou como negócio jurídico obrigacional (unincorporated joint venture - consórcio /grupo de sociedades de base contratual).

Contudo, por mais que se assemelhe aos grupos de sociedades, em um verdadeiro paralelismo de classificações, com este não se confunde. Passa-se a análise mais aprofundada da joint venture e de suas distinções com o grupo de sociedades.

\subsection{A joint venture e as relações internacionais}

A joint venture aparece como resultado da criação civilista e de interesse prático e consuetudinário do Common Law. É, portanto, uma figura originada da prática dos negócios e da própria jurisprudência americana $28 / 29$.

É uma forma de cooperação entre empresas independentes. Apesar das dificuldades de sua definição jurídica, que poderia gerar sua baixa adoção nas relações mercantis internacionais das empresas transnacionais, alcançou alta internacionalização. Mais ainda, a internacionalização deste contrato foi possível exatamente pela flexibilidade de sua constituição, proporcionando uma perfeita adequação aos negócios internacionais (negócios estes que demandam elevada diversidade de formas jurídicas para sua constituição).

Sua internacionalização se promoveu por meio do desenvolvimento da indústria petrolífera e de minerais.

de 17/12/1976 . Dispõe sobre as Sociedades por Ações. Regula o consórcio de empresas no artigo 278 e seguintes, que é aplicado, supletivamente, para a constituição de outros tipos de consórcio, mesmo quando não envolvam sociedades anônimas. Ademais, o Estatuto da Terra, Lei $\mathrm{n}^{\circ} 4.504$, de 30 de novembro de 1964, publicada no DOU em 31/11/1964, também regula o consórcio, em seu artigo 14, $\ 1^{\circ}$ : “\$1 PPara a implementação dos objetivos referidos neste artigo, os agricultores e trabalhadores rurais poderão constituir entidades societárias por cotas, em forma consorcial ou condominial, com a denominação de "consórcio" ou "condomínio", nos termos dos arts. $3^{\circ}$ e $6^{\circ}$ desta Lei. (Incluído pela Medida Provisória ${ }^{\circ}$ 2.183-56, de 2001)".

28 Veja: BAPTISTA, Olavo; RIOS SIERRALTA, Aníbal. Aspectos jurídicos del comercio internacional. Lima: Fondo Editorial, 1992. p. 185.

29 Veja a respeito do desenvolvimento internacional do contrato de joint venture: SIERRALTA RÍOS, Aníbal. Joint Venture internacional. Buenos Aires: Ediciones Depalma, 1996. p. 30-38. 
As atividades desenvolvidas por estas sociedades no estrangeiro não se qualificavam na estrita operação de importação/exportação, a qual se assemelha a uma conversa entre vizinhos (frente a frente), cada qual em sua casa, em seu território. Ao contrario, as sociedades minerarias e petrolíferas tiveram que ir mais além do habitual, isto é, erigir nesse universo estranho (estrangeiro) as estruturas jurídicas suscetíveis de acolher seus investimentos ${ }^{30}$.

A partir desse entendimento, a doutrina internacional tem definido a joint venture transnacional, concentração mais ampla do que aquela dada pelo direito anglo-saxão (originário).

A internacional joint ventures passa a ser entendida como mecanismo de cooperação entre empresas, o qual tem caráter contratual, sem forma específica. Possui natureza associativa (divisão dos meios e dos riscos), apresentando objetivos e duração limitada ou ilimitada ${ }^{31}$.

Nem sempre a consecução dos benefícios é o elemento essencial da joint venture internacional. É possível a existência de joint ventures em que os benefícios não aparecem como um fim imediato, se não meramente mediato. Esta possibilidade se encontra presente na criação de uma unidade comum de fabricação; centros comuns de investigação; centrais de compra; etc. Os co-ventures ganharão com a economia que poderá resultar de tais associações e com a redução dos custos que se observará ${ }^{32}$.

Outro elemento caracterizado da joint venture originária seria seu caráter ad hoc. Tal ponto nem sempre estará presente na international joint venture, uma vez que perdeu parte de sua relevância na prática comercial internacional. Assim, os contratos associativos para exploração de recursos naturais, que teriam caráter duradouro, conduzindo a uma instalação estável da empresa no mercado onde está localizado o investimento, poderia constituir-se sob a forma de international joint venture ${ }^{33}$.

30 BONVICINI, Daniele. Le joint venture: tecnica giuridica e prassi societaria. Milano: Giuffrè, 1977. p. 8.

31 BASSO, Maristela. Joint venture. Porto Alegre: Livraria do Advogado, 1994. p. 35.

32 BAPTISTA, Luiz Olavo; DURAND-BARTHEZ, Pascal. Les associations dienterprises (joint ventures) dans le comerse international. Paris: FEC, 1991. p. 63.

33 ASTOLFI; Andrea. Contratto internazionale de joint venture. Revista delle Societá, Milano, ano 22, p. 844, 1977.
Pode-se concluir esse ponto afirmando que, em sua internacionalização, a joint venture passou a ser mais flexível que em sua origem no direito anglo-saxão. Por sua vez, tal flexibilização transformou o entendimento do instituto ainda mais difícil, bem como sua definição.

No âmbito internacional se tomou o nome e o conceito global da joint venture corporation, mas não a natureza jurídica da joint venture original, impossível de passar para o campo internacional, ao não poder contrapô-la à partnership. No entanto, após essa fase de internacionalização, ficaram algumas características, as mais importantes: flexibilidade, controle conjunto e dever de fidelidade ${ }^{34}$.

\subsection{Disciplina jurídica da joint venture}

A joint venture, no sentido que é entendida hoje, deriva, em grande medida, de seu desenvolvimento a partir do pós-guerra ${ }^{35}$. Em virtude de sua flexibilidade e facilidade de constituição, a definição da joint venture continua em constante evolução ${ }^{36}$. A figura, no campo internacional, carece de uma disciplina unitária.

Em uma perspectiva europeia, vista sob a ótica do Direito inglês, o sugestivo nome joint venture implica exteriorizar o esforço comercial de duas ou mais partes. O termo seria utilizado para indicar cooperação entre dois ou mais partícipes; cooperação, da qual, o primeiro efeito seria a criação dos meios para facilitar a união de interesses ou mudanças de recursos ${ }^{37}$.

Outra forma de definir as joint ventures será levando-se em consideração o local de constituição do empreendimento comum: se se trata de um país com economia avançada ou se um país em vias de desenvolvimento ${ }^{38}$.

Desta forma, na primeira hipótese, em países de economia avançada, a joint venture constitui, geralmente, um instrumento de concentração dos investidores (os investidores terão a possibilidade de recorrer a um novo instrumento jurídico para concentrar seu capital)

34 MIQUEL RODRÍGUEZ, Jorge. La sociedad conjunta: Joint venture corporation. Madrid: Editorial Civitas SA, 1998. p. 100.

35 HERZFELD, Edgar. Joint ventures. 2. ed. Bristol: Jordans, 1991. p. 3.

36 LE PERA, Sergio. Joint ventures y otras formas de cooperación entre empresas independientes. Buenos Aires: La Ley, 1977. p. 71.

37 KLING, Edward; BURLEY, Stephen. Joint venture in Europe. London: Butterworths, 1991. p. 1.

38 Entre outros: STRENGER, Irineu. Contratos Internacionais do comércio. 2. ed. São Paulo: Revista dos Tribunais, 1992. p. 351. 
Por outro lado, nos PVDs, as joint ventures conformam instrumentos de cooperação industrial essencial para a realização de finalidades econômicas de crescente importância, tais como a ampliação do mercado trabalhista, a atualização tecnológica, a produção em economia de escala, etc. Ademais, seria uma forma de regulamentação dos investimentos estrangeiros, com o fim de favorecer a participação local (do receptor de investimentos) na gestão do empreendimento, garantindo sua presença no âmbito de desenvolvimento nacional.

Finalmente, não somente nos países de economia avançada, mas também nos PVDs , a joint venture é definida como acordos comerciais entre empresas, com vocação para a realização das mais variadas formas de colaboração e inter-relação econômica.

Assim, tais acordos podem possuir natureza puramente contratual (uncorporated joint venture - consórcio de empresas) ou, inversamente, dar origem à criação de um novo ente societário (incorporated joint venture - joint venture societária). Podem ser celebrados entre empresas pertencentes a um mesmo país ou, com maior frequência, entre empresas de nacionalidade distinta. Podem versar sobre múltiplos setores da atividade econômica, da produção e da I\&D até a colaboração tecnológica e administrativa ${ }^{39}$.

Alguns pontos caracterizadores ${ }^{40}$ da joint venture são sua origem e seu caráter contratual; definição do direito dos partícipes, independentes entre si; o sistema de governança e gestão conjunta; sua natureza associativa; a determinação de seu objeto e/ou duração; o caráter não formal do contrato; e facilidade de sua constituição.

Depois de analisadas as definições propostas e já com a certeza de não ser esta definitiva em virtude da flexibilidade e da facilidade de constituição de tal instrumento, entende-se que a international joint venture é um acordo de cooperação (sem forma própria - unincorporated joint venture) ou de associação (corporated joint venture) entre duas ou mais pessoas, físicas ou jurídicas, de direito público ou privado. Os partícipes podem exercer a administração conjunta do empreendimento e têm o dever de buscar um objetivo comum. Ademais, atuam na expectativa de benefícios meramente mediatos. Finalmente, podem constituir-se entre pessoas nacionais ou estrangeiras, sendo a segunda hipótese a mais frequente.

39 ANTUNES, José A. Engracia. Os grupos de sociedades. Coimbra: Almedina, 1993. p. 71-72.

40 Nesse sentido: BAPTISTA, Luiz Olavo. 1981. Les joint venture dans les relations internacionales. Paris II, p. 87-88 (Tesis de doctoramiento - Université de Droit d'économie et des Sciences Sociales de Paris).

\subsection{Tipologia}

Derivada da flexibilidade de constituição da joint venture existiria classificação de seus tipos, a saber:

a) Em relação ao ponto de vista organizativo: incorporated joint venture e unicorporated joint venture ${ }^{41}$;

b) Segundo os setores da atividade: manufatureiras; exploração de recursos naturais; agrupações bancárias; agrupações para construção de obra certa; investigação e produção comum; de investimento; de serviços e; comerciais $^{42}$;

c) Em relação à forma de concentração: horizontal e vertical ${ }^{43}$;

d) Em relação ao grau de participação em dominação: participativa e independente ${ }^{44}$.

\subsection{Joint venture e o grupo de sociedades}

O termo joint venture, como já referido, se formou na prática internacional para designar um vasto setor de acordos comerciais entre empresas, com vocação para realizar as mais variadas gamas de colaborações e interrelações econômicas.

Tais acordos podem possuir natureza puramente contratual (unincorporated joint venture) ou, inversamente, dar origem à criação de um novo ente societário (incorporated joint venture). Podem ser celebradas entre empresas pertencentes ao mesmo país ou, como é mais comum, entre empresas de diferentes nacionalidades. Podem versar sobre múltiplos setores da atividade econômica, de produção ou até da colaboração tecnológica e administrativa ${ }^{45}$.

41 BONVICINI, Daniele. Le joint venture: tecnica giuridica e prassi societaria. Milano: Giuffrè, 1977. p. 181.

42 MORAES NETO, Deraldo Dias de. Joint venture. Revista do Mestrado em direito da UFBA, Salvador, n. 3, p. 248-251, jul./jun. 1993. 43 CHUliá VICENTE, E. ; BELTRÁN ALANDETE, T. Aspectos jurídicos de los contratos atípicos., 4. ed. Barcelona: José Maria Bosch editor, 1999. p. 206. v. 1.

44 LAMY FILHO, Alfredo; PEDREIRA, José Luiz Bulhões. $A$ Lei das S.A. Rio de Janeiro: Renovar, 1992. p. 353.

45 Veja entre outros: BROWN, J. T. International Joint Ventures Contracts in English Law. DPCI, n. 2, p. 193-244, 1979. ; FRIEDMANN, W. G.; BEGUIN, J. P. International Business Joint Ventures in Developing Countries. New York: Columbia University Press, 1971. p. 3.; JAEGER, Walter. Joint Venture: origine, nature, developments. 4 Washburn Law Journal, n. 1, p. 9-44, 1964. ; PROPERSI, Antonio. Le Joint Ventures: gli accordi fra imprese. Roma: Buffetti, 1987. p. 67; PEREIRA, Amorim. O Contrato de Joint 
A figura da joint venture, ainda que não confundida com o grupo de sociedade, se entrelaça com ele e de forma específica com o caso das chamadas filiais comuns (incorparated joint venture) ${ }^{46}$.

Assim, por um lado, a constituição de filiais comuns constitui uma forma privilegiada de implementação dos grupos de sociedades multinacionais. $\mathrm{O}$ mesmo ocorre pelos obstáculos legais impostos aos investimentos estrangeiros pelos sistemas nacionais de licenças nacionais (especialmente se exige uma participação mínima do capital nacional) ${ }^{47}$. Além disso, as condições econômicas próprias das empresas envolvidas, os grupos são obrigados a garantir a sua presença nos mercados locais por meio da criação de empresas comuns com parceiros nacionais ${ }^{48}$. Por outro lado, a filial comum constitui um instrumento de colaboração dos próprios grupos societários entre $\mathrm{si}^{49}$.

Finalmente, em ambos os casos, constituído e controlado por duas ou mais empresas sócias, a filial comum dará sempre origem a problemas de domínio intersocietário (em particular sempre que as participações sejam igualitárias, gerando problemas de domínio múltiplo horizontal).

\section{Conclusão: o grupo de sociedades e as relações de domínio múltiplo}

O direito das sociedades tradicionalmente se baseia no postulado da independência da sociedade mercantil. Constituída a sociedade mercantil individual e autônoma, aparece composta de uma plêiade de sócios individuais e gerenciada por administradores independentes, que procuram maximizar os lucros sociais.

A emergência do fenômeno do controle intersocietário, surgida na sequência do movimento de

Venture. Lisboa: ICEP, 1988.

46 PINHEIRO, Luís de Lima. Joint Venture: contrato de empreendimento comum em direito internacional privado. Lisboa: Edições Cosmos, 1998. p. 186.

47 WALLACE, Cynthia D. Legal Control of the Multinational Enterprise. Boston/London: Martinus Nijhoff, 1982. p. 121.

48 Principalmente pelo fato que, geralmente, a empresa estrangeira possui a capacidade tecnológica ou comercial, mas não tem o conhecimento necessário do mercado local, necessitando da empresa nacional. Veja: ASTOLFI, Andrea. Il Contratto Internazionale de Joint Venture. Revista delle Societá, Milano, ano 22, p. 843, 1977.

49 JEANTIN, Michel. La filiale commune, moyen de colaboration entre sociétés et groupes de sociétés. Paris: Libraries Techniques, 1976. p. 46. concentração econômica dos dias atuais, vem mudar profundamente esta situação.

Efetivamente, verifica-se que o capital social de muitas sociedades não se encontra disperso em pequenos investidores singulares, mas sim nas mãos de outras pessoas coletivas que desenvolvem uma atividade econômica-empresarial. Tais pessoas coletivas, especialmente outras sociedades mercantis, buscam, por meio de seu patrimônio, assegurar o exercício de um domínio e controle sobre a gestão de outras empresas societárias, até então independentes. Neste sentido, a criação de um estatuto de dependência intersocietária pode constituir uma fonte de graves desequilíbrios e contradições para as sociedades controladas.

Estes problemas podem surgir em dois planos:

1) Por um lado, no âmbito da estrutura patrimonial e organizacional da própria sociedade dependente, bem como outros destinatários jurídico-societários que com ela estão em contato (o respectivos sócios, ou credores sociais).

2) Por outro lado, no âmbito da eficiência das normas jurídico-societárias em geral, já que o domínio intersocietário é suscetível de ser usado como uma ferramenta de incumprimento das normas que foram concebidas originariamente para regular a situação dos entes independentes (o direito societário tradicional).

Além disso, em geral, as relações de domínio entre as sociedades revestirão um caráter direto e bilateral. Assim, uma empresa (dominante) exerce direta e imediatamente uma influência dominante sobre outra sociedade (dependente). Trata-se, pois, de relações estabelecidas diretamente de sociedade para sociedade (ligações diretas), envolvendo apenas os dois entes jurídico-societários (relações bilaterais).

Não obstante, a realidade societária é muito mais interessante.

$\mathrm{Na}$ verdade, há casos frequentes em que a relação de domínio assume uma configuração variada. Este fato ocorre por serem distintas as sociedades envolvidas, além do exercício de influência dominante gerar efeitos divergentes daqueles praticados em uma situação normal de domínio individual (empresa individual).

Assim, pode-se afirmar:

a) À medida em que (se a idéia for de proporção, substitua por à medida que) a influência de domínio é exercida indiretamente pela sociedade dominante, por meio da interposição de uma terceira sociedade, tem-se um domínio múltiplo vertical; 
b) Se a influência de domínio múltiplo é exercida conjuntamente pela sociedade dominante e outra sociedade dependente, tem-se uma situação de domínio múltiplo horizontal; $\mathrm{e}$

c) Finalmente, quando a influência de domínio é exercida simultaneamente por distintas sociedades, tem-se uma situação de domínio e dependência plurilaterais.

Passa-se a uma análise breve dessas distintas formas de domínio no seio do grupo de sociedades.

a) Com a designação dominio múltiplo verticat ${ }^{0}$ pretende-se abarcar todas aquelas relações em que uma sociedade exerce uma influência dominante sobre outra sociedade, a qual, por sua vez, exerce um mesmo tipo de influência sobre uma terceira sociedade (e assim sucessivamente), estabelecendo uma cadeia vertical de domínio ${ }^{51}$.

b) Com a designação domínio múltiplo horiz̧ontal, pretende-se abarcar aqueles casos em que a sociedade se encontra dominada direta e simultaneamente por outras duas sociedades que são, entre si, independentes.

Sob o ponto de vista econômico, a filial comum constitui um instrumento privilegiado de cooperação entre empresas, traduzindo a situação de uma empresa que é constituída ou controlada por duas ou mais empresas diferentes e independentes entre si. Assim, pretendem realizar determinados objetivos comuns, tais como a cooperação em diversas áreas da produção; obtenção do serviço de apoio às respectivas atividades produtivas próprias; ou o simples objetivo de realização dos ganhos conjuntos; etc. ${ }^{52}$.

50 A problemática do domínio múltiplo vertical constitui um único aspecto das relações de coligação intersocietaria de caráter vertical ou piramidal, uma vez que reporta tão somente às relações de domínio entre as sociedades. As relações de coligação vertical entre as sociedades existem, todavia, relativamente a todo tipo de sociedades coligadas, englobando igualitariamente as sociedades em relação de participação simples e recíprocas, as sociedades em relação de grupo, bem como as sociedades que estabeleçam, entre si, diferentes tipos de relação de coligação ou de cooperação.

51 Exemplificando: Se a empresa $A$ detém $60 \%$ do capital social da sociedade $B$ e esta por sua vez, detém $60 \%$ do capital da sociedade $C$, então estaria se diante de um caso de domínio múltiplo vertical, onde $A$ domina diretamente $B$ e indiretamente $C$. Assim, a mesma sociedade (mãe), está simultaneamente em relação de domínio com uma sociedade (filial) e ainda, em virtude do efeito piramidal associado à influência indireta, tem um domínio indireto com outra sociedade dependente de sua filial (que no exemplo será a sociedade C).

52 Cumpre sublinhar que são vários os instrumentos jurídicos que permitem um tal objetivo de cooperação interempresarial, tais como: o contrato de unincorporated joint venture (consórcio de empresas); ou o contrato de grupo paritário; etc.
Sob o ponto de vista jurídico, a filial comum possui relevância não somente para o direito da concorrência ${ }^{53}$, mas também, sempre que as empresas envolvidas revistam a forma societária, para o próprio direito das sociedades.

Em relação ao domínio múltiplo horizontal, podese dizer que a problemática jurídico-societária de fundo, subjacente em tais relações, consiste em saber se será admissível que uma sociedade esteja sujeita, simultaneamente, ao exercício de uma influência dominante por parte de duas sociedades reciprocamente independentes. Em outras palavras, se é admissível a dependência plural ${ }^{4}$. Protótipo desta situação é o caso das filiais 50:50 (fifthy-fifthy subsidiaries), sociedade cujo capital social é controlado total e igualitariamente por duas outras sociedades.

c) Finalmente, cumpre destacar que a pluralidade de sujeitos de uma relação de domínio, já seja de sujeitos ativos (sociedades dominantes), já seja de sujeitos passivos (sociedades dependentes), pode originar a formação de domínio e dependência plurilaterais. Assim, são possíveis situações de domínio-dependência simultâneo. Nestes casos, a sociedade $A$ domina a sociedade $B$ e esta, por sua vez, domina a sociedade $C$. Desta forma, e neste caso, a sociedade $B$ é, simultaneamente, dominante (relativamente à $C$ ) e dependente (em relação à $A$ ). Também cabem situações de dependência plural. Assim, no mesmo exemplo, a sociedade $C$ é, ao mesmo tempo, dependente da sociedade $A$ e dependente da sociedade $B$.

Outra possibilidade é a existência de situações de domínio plural. Por exemplo, a sociedade $A$ detém maioria dos votos nas sociedades $B, C$ e $D$, sendo dominante, por isso mesmo, em relação a todos elas.

53 Veja: CORDEIRO, António Robalo. As Coligações de Empresas e os Direitos Português e Comunitário da Concorrência. XXIX Revista de Direito e Estudos Sociais, Lisboa, p. 82, 1987.; BALEKJIAN, UAE H. Parent and subsidiary companies under european competition law. In: Legal Aspects of International Business Transactions. North-Holland: Elsevier Science, 1984. p. 379.

54 Há que distinguir, todavia, os casos de dependência plural imprópria e dependência plural própria. Os primeiros são consequência de relações de domínio múltiplo vertical, que não suscitam dúvidas, como acima visto (exemplo: $A$ domina $B$ e esta domina $C$. Logo, $C$ é dependente, simultaneamente, de $A$ e $B)$. Os segundos demonstram uma situação distinta, já que as sociedades dominantes são independentes entre si (exemplo: $A$ e $B$ detém, cada uma, $50 \%$ do capital de $C$. Poderia se considerar que neste caso $C$ é dependente de $A$ e $B)$. 
Em conclusão, é significativo mencionar a necessidade de entendimento do grupo de sociedades desde uma perspectiva econômica para uma aproximação à delimitação desta figura jurídica.

A utilização do instrumento do grupo de sociedades está clara como o mecanismo mais utilizado, pelos operadores do mercado, para os investimentos internacionais. $\mathrm{O}$ grupo de sociedades é, neste momento, o instrumento jurídico por excelência que permite com maior fluidez a internacionalização do capital.

Conclui-se, afirmando que o grupo de sociedades se distingue dos instrumentos de concentração e cooperação analisados, apresentando-se como um instrumento de concentração de terceira geração, permitindo a concentração na pluralidade, ou seja, a criação de entes plurissocietários. 


\section{Referências}

ANDREU MARTÍ, Ma del Mar. La nulidad de la fusión de sociedades. Pamplona: Aranzadi Editorial, 2002.

ANTUNES, José A. Engrácia. Os grupos de sociedades. Coimbra: Almedina, 1993.

ANTUNES, José A. Engrácia. Os direitos dos sócios da sociedade-mãe na formação e direção dos grupos societarios. Porto: UCP, 1996.

ASTOLFI; Andrea. Il contratto internazionale de Joint Venture. Revista delle Societá, Milano, ano 22, 1977.

BALEKJIAN, UAE H. Parent and subsidiary companies under european competition law. In: Legal aspects of international business transactions. North-Holland: Elsevier Science, 1984.

BAPTISTA, Luiz Olavo; DURAND-BARTHEZ, Pascal. Les associations d'enterprises (Joint Ventures) dans le comerse international. Paris: FEC, 1991.

BAPTISTA, Luiz Olavo. 1981. Les joint venture dans les relations internacionales. Paris II, p. 87-88 (Tesis de doctoramiento - Université de Droit d économie et des Sciences Sociales de Paris).

BAPTISTA, Luiz Olavo; RIOS SIERRALTA, Aníbal. Aspectos jurídicos del comercio internacional. Lima: Fondo Editorial, 1992.

BASSO, Maristela. Joint venture. Porto Alegre: Livraria do Advogado, 1994.

BEGG, P. F. C. Corporate Acquisitions and Mergers. London: Graham \& Trotman, 1986.

BERCOVITZ, Alberto. La Fusión de Sociedades. In: La Reforma del Derecho Español de Sociedades de Capital. Madrid: Universidad Complutense, 1987.

BERTREL, Jean; JEANTIN, Michel. Fusions et acquisitions de sociétés commerciales. Paris: Litec, 1989.

BIANCHI, Giorgio. Le Operazioni di Fusione. Torino: Unione Tipografico-Editrice Torinese, 2000.

BONVICINI, Daniele. Le joint venture: tecnica giuridica e prassi societaria. Milano: Giuffrè, 1977.
BORGES, João Eunápio. Curso de direito comercial terrestre. Rio de Janeiro: Forense, 1959. v. 1.

BRASIL. Lei $n^{\circ}$ 4.504, de 30 de novembro de 1964. Disponível em:< http://www.planalto.gov.br/ ccivil_03/leis/14504.htm>

BRASIL. Lei 6.404, de 15 de dezembro de 1976. Disponível em:< http://www.planalto.gov.br/ccivil_03/leis/ 16404consol.htm>

BROSETA PONT, Manuel. Manual de derecho mercantil. 10. ed. Madrid: editorial tecnos, 2000.

BROWN, J. T. International Joint Ventures Contracts in English Law. DPCI, n. 2, 1979.

CARVALHO, Orlando de. Critério e estrutura do estabelecimento comercial: o problema da empresa como objecto de negócios. Coimbra: Coimbra Editora, 1967.

CHAMPAUD, Claude. Le pouvoir de concentration de la société par actions. Paris: Librairies Sirey, 1962.

CHEMINADE, Y. La Nature Juridique des Fusion. RTDC, 1970.

CHULIÁ VICENTE, E. ; BELTRÁN ALANDETE, T. Aspectos jurídicos de los contratos atípicos. 4. ed. Barcelona: José Maria Bosch editor, 1999. v. 1.

CORDEIRO, António Robalo. As Coligações de Empresas e os Direitos Português e Comunitário da Concorrência. XXIX Revista de Direito e Estudos Sociais, Lisboa, 1987.

DAEMZ, Herman. The Holding Company and Corporate Control. Boston: Leiden, 1978.

GALGANO, Francesco. Qual è l’Oggetto Sociale della Holding? In: CeIm, v. 2, p.327-343, 1986.

EISENBERG, Melvin. The Structure of the Corporation: a legal análisis. Boston: Little Brown, 1975.

FERRAZ, Daniel Amin. El grupo de sociedades como mecanismo de desarrollo de los países de periferia. Revista de Direito, Viçosa, MG, v. 1, n. 1, p. 205-238, 2004.

FERRAZ, Daniel Amin. La concentración empresarial en el comercio internacional: el control de los grupos de sociedades 
en los EE.UU., la UE y MERCOSUR: un análisis comparado. Valencia: Editorial de la Universidad de Valencia, 2004.

FERREIRA, Durval. Cisão de Sociedades. Coimbra: Almedina, 1985.

FERREIRA, Waldemar Martins. Tratado de Direito Mercantil Brasileiro: o comerciante. Rio de Janeiro: Livraria Freitas Bastos, 1939. v. 2.

FRAILE BARTALOMÉ, Gregorio; CLEMENTE CLEMENTE, Vicente: Fusiones y escisiones en las sociedades anónimas. Valencia: CISSPRAXIS, 2001.

FRIEDMANN, W.G.; BEGUIN, J.P. International business joint ventures in developing countries. New York: Columbia University Press, 1971.

HAMEL, Joseph. Les Sociétés d'Investissement. Paris: A.N.S.A. $128,1960$.

HERZFELD, Edgar. Joint ventures. 2. ed. Bristol: Jordans, 1991.

JAEGER, Walter. Joint Venture: origine, nature, developments. 4 Washburn Law Journal, n. 1, 1964.

JEANTIN, Michel. La filiale commune, moyen de colaboration entre sociétés et groupes de sociétés. Paris: Libraries Techniques, 1976.

KLING, Edward; BURLEY, Stephen. Joint venture in Europe. London: Butterworths, 1991.

LAMY FILHO, Alfredo; PEDREIRA, José Luiz Bulhões. A Lei das S.A. Rio de Janeiro: Renovar, 1992.

LANGEFELD-WIRTH, Klaus. Les Joint Ventures internationals. Paris: GLN Joly editions, 1992.

LARGO GIL, Rita. La fusión de sociedades mercantiles: fase preliminar, proyecto de fusión e informes, 2. ed., Madrid: Civitas, 2000.

LE PERA, Sergio. Joint ventures y otras formas de cooperación entre empresas independientes. Buenos Aires: La Ley, 1977.

LIBONATI, Berardino. Holdings e Investment Trusts. Milano: Giuffrè, 1977.
MARTIN, G. La Notion de Fusion. RTDC, 1978.

MENDONÇA, José Xavier Carvalho de. Tratado de Direito Comercial Brasileiro. Rio de Janeiro: Livraria Freitas Bastos, 1957. v. 1.

MIQUEL RODRÍGUEZ, Jorge. La sociedad conjunta: Joint venture corporation. Madrid: Editorial Civitas SA, 1998.

MISHKIN, Walter. Techniques in corporate reorganizations. New York: Publisher House, 1972.

MORAES NETO, Deraldo Dias de. Joint venture. Revista do Mestrado em direito da UFBA, Salvador, n. 3, jul./jun. 1993.

PALEA, Vera. Il rapporto di cambio nelle operazioni di fusione e di scissione. Torino: Giappichelli Editore, 2000.

PEREIRA NETO, Mario. Joint Ventures com a União Européia. São Paulo: Aduaneiras, 1995.

PEREIRA, Amorim. O Contrato de Joint Venture. Lisboa: ICEP, 1988.

PINHEIRO, Luís de Lima. Joint Venture: contrato de empreendimento comum em direito internacional privado. Lisboa: Edições Cosmos, 1998.

PROPERSI, Antonio. Le Joint Ventures: gli accordi fra imprese. Roma: Buffetti, 1987.

RODRÍGUEZ ARTIGAS, Fernando; URIA, Rodrigo; MENÉNDEZ, Aurelio; OLIVENCIA, Manuel. Comentario al régimen legal de las sociedades mercantiles: transformación, fusión y escisión de la sociedad anónima. Madrid: Editorial Civitas, 1993. v. 3. t. 9.

ROJO, Angel. La escisión de sociedades. La Reforma del Derecho Español de Sociedades de Capital. Madrid: Universidad Complutense, 1987.

SACARDULLA, Francesco. La transformazione e la fusione delle società. In: CICU, Antonio; MESSINEO, Francesco; MENGONI, Luigi. Trattato di diritto civile e comérciale. Milano: Giuffrè editore, 2000. v. 30, t. 2.

SÁNCHEZ MIGUEL, María Candelas. Las fusiones transfronterizas y el derecho de la competência. In: Derecho de Sociedades. Madrid: McGrawHill, 2002. v. 5. 
SANTAGATA, Carlo. La Fusione fra Società. Napoli: Morano, 1964.

SCHIPPER, K.; SMITH, A. The Corporate Spin-Off Phenomenon. In: The Revolution in Corporate Finance. Oxford: Basil Blackwell, 1986.

SENN, Georges. Les sociétés de investissement en droit francais et droit comparé. Paris: Sirey, 1956.

SIEGEL, Harold. When corporations divide: a financial and legal analysis. 79 HarvLR, 1966.

SIERRALTA RÍOS, Aníbal. Joint Venture internacional. Buenos Aires: Ediciones Depalma, 1996.

STRENGER, Irineu. Contratos Internacionais do comércio. 2 ed. São Paulo: Revista dos Tribunais, 1992.

TANTINI, Giorgio. Transformazione e fusione delle società, In: Tratatto di Diritto Comérciale e di Diritto Pubblico dell'Economia. Padova: Cedam, 1985. v. 8.
Tercera Directiva 78/855/CEE do Conselho, de 09 de outubro de 1978 (Diário Oficial L 295 de 20.10.1978).

VAÑÓ VAÑÓ, Maria José. Fusión heterogénea y cesión global en el sector bancario. Valencia: Tirant lo Blanc, 2001.

VENTURA, Raúl. Fusão, cisão, transformação de sociedades. Coimbra: Almedina, 1990.

VENTURA, Raúl. Participações unilaterais de sociedades em sociedades e sociedades gestoras de participações noutras sociedades. XXIX RSI, 1980.

WALLACE, Cynthia D. Legal Control of the Multinational Enterprise. Boston/London: Martinus Nijhoff, 1982.

WEINBERG, M. A. Take-overs and Mergers. London: Sweet \& Maxwell, 1979. 
Para publicar na Revista de Direito Internacional, acesse o endereço eletrônico www.rdi.uniceub.br ou www.brazilianjournal.org.

Observe as normas de publicação, para facilitar e agilizar o trabalho de edição. 